\title{
Changing perspectives: tracing the evolution of citizen radiation measuring organizations after Fukushima
}

\author{
J. Kenens ${ }^{1,2, *}$ \\ ${ }^{1}$ SCKCEN - Belgian Nuclear Research Centre, Boeretang 200, Mol, Belgium. \\ ${ }^{2}$ Centre for Sociological Research (CeSO), KU Leuven, Parkstraat 45, Leuven, Belgium.
}

\begin{abstract}
Although bottom-up citizen science in the field of radiation monitoring is not a new phenomenon, the organizations established in the wake of the Fukushima accident exceed preceding organizations in numbers, in space and in data production. Almost 10 years after the Fukushima nuclear accident, citizen radiation measuring organizations continue their activities stressing the importance of transparency, education and participation, despite the issues they are facing. Drawing on research on citizen science and results from fieldwork conducted in Japan, this paper reflects on the evolution of grassroots citizen science initiatives, contrasting their activities in the immediate aftermath of the Fukushima disaster to present day. By showing how some organizations have grown and others faded away, it demonstrates the intertwining and flexibility of citizen science initiatives in addressing concerns and needs expressed by local communities.
\end{abstract}

Keywords: Fukushima nuclear accident / bottom-up citizen science / post-disaster recovery

\section{Introduction}

Citizen science, commonly referred to as the participation of citizens in scientific endeavor (Haklay, 2013; Kobori et al., 2016), has a long tradition in the fields of ecology and astronomy. Yet, in recent years, citizen science has experienced rapid expansion in terms of volunteers and projects, and presently covers an increasingly wide range of academic fields (Haklay, 2013; Silvertown, 2009). Although its popularity is linked to policy shifts, such as favoring open and inclusive science research (Felt, 2017), it also ties in with the advent of the internet, new communication technologies and technological advancements, creating an easier access for non-experts to participate in scientific research (Haklay, 2013). Next to technological and policy developments, events, such as environmental pollution (McCormick, 2012) and nuclear accidents, including Three Mile Island and Fukushima, can also trigger a public into action (Walsh, 1981; Gricar and Baratta, 1983; Angelique and Culley, 2010, 2014a, 2014b). Particularly the Fukushima accident has created an unprecedented upsurge of citizen science initiatives within the affected area and far beyond, giving rise to international organizations such as Safecast and dozens of local citizen radiation measuring organizations (shimin hōshanō sokutei jo) in Japan (Kimura, 2016; Kenens et al., 2020). What these

\footnotetext{
* Corresponding author: joke.kenens@kuleuven. be
}

initiatives have in common is their issue-driven approach to science (Hasegawa, 2004; 2014; Morita et al., 2013). In effect, the activism of these organizations is not necessarily inspired by an interest in science or technology, but rather an urgent call for more information, as traditional information sources fail to provide adequate and actionable data (Morita et al., 2013). Contrary to top-down initiated citizen science, they present therefore another strand of citizen science, one that emerges from the bottom-up, representing a "democratization of science" (Irwin, 1995).

In Japan, the first citizen-driven organizations measuring ionizing radiation date back to the 1970s. These pioneers, amongst others the Citizen Nuclear Information Center, aimed at providing an alternative source of information for Japanese society and were part of antinuclear activism (Avenell, 2016). They were later joined by other initiatives, mostly set up after the Chernobyl nuclear accident in 1986 (Hasegawa, 2004). Contrary to the first organizations, these latter groups mobilized another type of citizen to measure radiation, namely concerned mothers (Hasegawa, 2004; Leblanc, 1999). Although this second category is not characterized by the clear antinuclear message of the first category (Kimura, 2016; Kenens et al., 2020), they share a citizen-driven, citizeninitiated nature and independence from other governmental or scientific institutions with some of the earlier organizations. During the Fukushima accident, these initiatives, some with decades long experience of monitoring radiation levels in food products, were able to provide information on radiological 
contamination to citizens during the Fukushima accident and to advise citizens in setting up their own radiation measuring labs. While these Japanese initiatives represent local bottomup citizen radiation measuring organizations, citizen science in radiological protection is however not solely comprised of this kind of initiatives. Rather, they are accompanied by initiatives such as Gricar and Baratta's study (Gricar and Baratta, 1983) and OpenRadiation (Bottollier-Depois et al., 2019). These examples seek to connect formal institutions and citizens through interaction and collaboration on data production.

A concern expressed by professional scientists, when seeking to engage citizens in scientific research, is how to uphold the continued interest of citizens in the project (Geoghegan et al., 2016; Cooper, 2016). Especially when engaging a population in a disaster-struck environment, keeping in touch with local needs and concerns becomes essential to mobilize citizens, as focus shifts from short-term disaster management to long-term recovery. The same concern for continuity permeates bottom-up citizen science. However, as local bottom-up organizations are in immediate contact with the community and depend on their support, they can tap into these connections and use them as an advantage to adapt themselves to changing interests and concerns (Kenens et al., 2020; Morris-Suzuki, 2014). Thus their presence, and the type of activities they involve in, mirror how attention in community shifts from urgency towards a long-term perspective. Taking into account these observations, this paper shows how bottom-up citizen radiation measuring organizations in Japan have evolved since the Fukushima accident, distinguishing and discussing their endeavors from short- and long-term perspectives. In so doing, it highlights the flexibility of bottomup citizen science initiatives. For this purpose, it draws on literature research (Leblanc, 1999; Morita et al., 2013; Hasegawa, 2014; Morris-Suzuki, 2014; Kimura, 2016) and fieldwork conducted in Japan in February-March and November-December 2018. During this fieldwork, 14 organizations were visited and semi-structured interviews on various topics, including their activities and relevance to the community, were conducted with their members.

\section{Evolution of citizen radiation measuring organizations from short- to long-term recovery}

When a chain of events critically damaged the Fukushima Daiichi Nuclear Power Plant, resulting in the release of radioactive particles, the Tohoku area was grappling with the aftermath of the tsunami and the earthquake that struck the area. While food distribution and emergency aid were quickly set up, accounts of the immediate post-disaster situation generally depict the chaos and uncertainty amongst the inhabitants concerning the situation at the Fukushima Daiichi Nuclear Power Plant (Fukushima Booklet Committee, 2015). As some citizens were torn between leaving behind their parents or taking their children to safety (citizen scientist, Iwaki, March 2018), others, such as a citizen scientist in Fukushima city, worried whether or not they unknowingly exposed themselves and their families to ionizing radiation (citizen scientist, Fukushima city, March 2018). The risk advisors and information sessions set up in the aftermath of the Fukushima nuclear accident fell short in addressing the concerns experienced by the affected inhabitants (citizen scientist, Aizu Wakamatsu, February 2018; Pearce, 2018). In her paper, Morris-Suzuki (2014) points to the different notions of "uncertainty" experienced by the affected local population, which were not responded to by the authorities. The inapt way the national government subsequently evacuated inhabitants in areas close to the nuclear power plant of Fukushima (National Diet of Japan, 2012) and the information shortage regarding the spread of ionizing radiation, contributed to the breach in confidence that was expanding amongst the public. Subsequently, this resulted in a "failure of civic epistemology" (Morita et al., 2013), as traditional ways to gain public support fell short aiding a growing void of trustworthy information.

Stepping in to fill this information gap were citizens themselves by taking to hand measurement equipment, provided by amongst others municipalities through the Hakaru-kun project initiated by the Ministry of Education, Sports, Science and Technology to educate citizens concerning radiation, making available Geiger Counters to the public (citizen scientist, Tokyo, March 2018). Setting up new local citizen radiation measuring organizations, groups gathered the necessary funds to purchase the measuring equipment. The first organizations started operating weeks after the nuclear accident (CRIIRAD, 2011), but it took several months for most citizen groups to acquire measurement equipment, which often had to be purchased at high expenses. In addition to these initiatives, the few already existing radiation measuring citizen organizations continued their monitoring activities and proved a helpful vehicle to educate citizens on radiation and measuring methods. Paradoxically for some older organizations, the Fukushima nuclear accident revitalized their activities. For example, an organization in Koganei city originating from the 1990s, which depends on the benevolence of the city's funding for its measuring equipment, saw its continued existence increasingly endangered due to budget concerns (citizen scientist, Tokyo, December 2018).

The number of initiatives set up by citizens after the Fukushima nuclear accident quickly amassed over hundreds of organizations spread across Japan. A map displaying all organizations affiliated to the National Network of Parents to Protect Children from Radiation (Kodomotachi o hōshanō kara mamoru zenkoku nettowāku) counts over 300 initiatives (National Network of Parents to Protect Children from Radiation, sd). Though not all of these organizations are actively measuring radiation, their number hints at the extent and spread of citizen initiatives spread across Japan after the 2011 nuclear accident. Providing a means for citizens to cope with the potential risk of exposure to ionizing radiation and the uncertainty of the situation, citizen radiation measuring organizations boomed (Morris-Suzuki, 2014; Kimura, 2016; Morita et al., 2013). Not only did they facilitate information access to data produced by and for citizens, but they also tended to individual concerns by making readily available a service that individuals could rely on to suite their specific needs. For example, many of the interviewed members account how citizens could bring any item, such as vegetables, soil, Tshirts and shoes, to the lab for measurement. The radiation measuring organizations were organized around the issue of 
data scarcity, and their initial success as new information hubs for citizens, intertwined with the emergency situation and the related discrepancy between the information given by the state and the information demanded by the public. Bypassing traditional information sources such as the government and scientific institutions, these organizations provided an alternative means for data production, administered to specific requests and needs that were not being addressed by other (official or institutional) actors in the field of radiation measurement (Kimura, 2016).

While a member of a citizen radiation measuring organization in Iwaki draws upon the image of a "field hospital" to describe the sense of urgency, the precarious task undertaken by their organization during the initial phase after the nuclear accident and the ongoing stream of samples brought in by citizens (citizen scientist, Iwaki, March 2018), the situation has gradually changed. Subsequently, this is affecting the functioning of the organizations. While showing binders containing results of measurements conducted since their start in 2011, a representative of a citizen group in Nagoya describes their situation as follows:

"this [pointing to a binder] one of April 302012 is full, so it was filled within 5 months. This one, in four months, from May until 31 August, and then this one, the second year was still very busy. Turning to 2013, this binder contains the data until 31 April, so we were still measuring at a high pace. [...] This one, from 2014 until 2015, this binder covers one year. This one has 2017 written on it, so it's from 2015 until 2017, so it gathers more than 2 years. In one binder. For recent results, it's inside this one, we only measured this much since January this year [binder was less than half filled]. [laughs] So it has decreased this much? But all the other organizations are the same. Since we don't get any samples, there are also places that halt their activities." (Interview by author with member of citizen radiation measuring organization in Nagoya, November 2018).

By pointing out the binders stacked with data accumulated over the years and by contrasting the initial years and the last few years, the Nagoya representative visually illustrates the transition that citizen radiation organizations are experiencing. Since the Fukushima nuclear accident, the number of citizen radiation measuring organizations has decreased. The reasons for the general decline are manifold. The steady production of data by the Japanese government concerning the contamination in the affected areas and the decontamination of the area have altered the situation many of the citizen radiation measuring stations operate in. Considering that citizen radiation measuring organizations depend on samples brought in by citizens and crowdfunding to support their activities, they stand on the receiving end of the public's goodwill and are affected by the public's interest. Yet, as time passes and the memory of the Fukushima nuclear accident slowly fades, the need for data on radiation contamination decreases, resulting in an increasing number of citizen initiatives that are struggling as community members depend less upon their services.

The general declining interest in the Fukushima nuclear accident not only translates to decreasing number of samples brought in to citizen radiation measuring organizations by local residents, but also to funding problems and difficulties in recruiting new members. In the face of this trend, some organizations have, nonetheless, managed to adapt and expand their activities, shifting their focus from short- to long-term recovery, while continuously monitoring contamination by ionizing radiation. These activities encompass amongst others the monitoring of levels of ionizing radiation, education and mental healthcare. During interviews members attest how these activities are incorporated into the organization's scope in close negotiation with the community in order to provide the necessary services and information. Although the measurement of ionizing radiation remains at the core of their activities, interviews with citizen scientists point to additional objectives, other than addressing individual requests. They include monitoring the environment and crosschecking government's data on radiation contamination by generating their own data, and compiling records of the 2011 events for future generations. Whilst having documented and having established a general understanding of the affected areas since 2011, certain organizations also endeavor to recapitulate events and to address reminiscent information gaps. The Minna no Data Site, a network of about 30 independent citizen organizations, for example published in 2018 a book entitled "Citizens' radiation data map of Japan" (Suzetsu 17 token hōshanō sokutei mappu + yomitoki shu) compiling results of soil contamination in the Tôhoku region.

Alongside the continued monitoring of radiation levels, citizen groups have devoted considerable effort to education and information dissemination, passing on their expertise to other citizens. Every group the author visited during her fieldwork has experience in setting up study meetings and publishing brochures on exposure to radiation. Each group also maintains a website, explaining radioactivity, the effects of exposure and measuring methods. To accommodate and to adapt to the changing conditions and demands from their community, certain groups, such as in Iwaki, Aizu Wakamatsu and Fukushima city, have broadened the scope of their organization to incorporate activities that are loosely connected to radiation measurement and that tend to other problems experienced by the affected community. Citizen groups for example provide access to children summer camps as a temporary 'escape' from the exposure and stress of the post-disaster environment. Mental healthcare has, indeed, proven to be an important issue within the affected communities (Karz et al., 2014; Hayashi et al., 2020). For this purpose, an organization in Iwaki has dedicated two rooms in its office to offer counseling and massages for children and parents. ${ }^{1}$ In some cases, such as in Aizu Wakamatsu, healthcare services are arranged in collaboration with medical physicians. While these kinds of activities stretch the definition of "citizen radiation measuring organizations", they showcase the flexibility of citizen-initiated and -driven organizations, stressing the importance of connectivity with the local community and safeguarding the continued existence of citizen groups.

\footnotetext{
${ }^{1}$ During fieldwork in 2020, the author learned that the organization now has established a separate location to provide mental healthcare.
} 


\section{Conclusion}

Born in precarious circumstances following the Fukushima accident, bottom-up citizen radiation measuring organizations have laid the first steps to democratize a field of science that has been traditionally closed for laypersons and the public. While approaching the tenth anniversary of the disaster, citizen groups continue to monitor the contamination caused by the Fukushima nuclear accident. Notwithstanding that the number of organizations has diminished over the years, plagued by amongst others funding issues and recruitment problems, some citizen groups have adapted to circumstances and broadened their scope of activities, addressing different issues in response to community needs. Remaining in close connection with the local community helped these organizations to grow and take on new areas of expertise, demonstrating the flexibility of citizen science groups by continuously developing and rethinking their organization, initially created to address information scarcity and distrust towards public institutions, to adopt a long-term perspective. Nevertheless, at their core remains a demand for transparency and information access. As the community resides at the heart of these organizations, the creation and development of bottom-up citizen groups voice the concerns of the affected population, and hint at the evolution of the community from the immediate aftermath to long-term recovery, indicating how citizen science can play a role in post-disaster recovery.

Acknowledgments. Research reported here received funding from the European project ENGAGE (data analysis) and a Bilateral Joint Research Agreement between the Research Fund - Flanders (FWO) and the Japanese Society for the Promotion of Science (JSPS) (VS05517N) (data collection). ENGAGE is part of H2020 CONCERT project. This project received funding from the EURATOM research and training programme 2014-2018 under grant agreement No. 662287.

Disclaimer (Art. 29.5 GA). This publication reflects only the author's view. Responsibility for the information and views expressed therein lies entirely with the authors. The European Commission is not responsible for any use that may be made of the information it contains.

\section{References}

Angelique HL, Culley MR. 2010. Participation, power, and the role of community psychology in environmental disputes: a tale of two nuclear cities. Am. J. Comm. Psy. 47(3-4): 410-426.

Angelique HL, Culley MR. 2014a. Nuclear power: renaissance or relapse? Global climate change and long-term three mile island activists' narratives. Am. J. Comm. Psy. 45: 231-246.

Angelique HL, Culley MR. 2014b. To Fukushima with love: lessons on long-term antinuclear citizen participation from Three Mile Island. J. Comm. Psy. 24(2): 209-227.

Avenell S. 2016. Antinuclear radicals: scientific experts and antinuclear activism in Japan. Sci. Tech. Soc. 21(1): 88-109.

Bottollier-Depois JF, Allain E, Baumont G, Berthelot N, Darley G, Ecrabet F, Jolivet T, Lebeau-Livé A, Lejeune V, Quéinnec F, Simon C, Trompier F. 2019. The OpenRadation Project: monitoring radioactivity in the environment by and for the citizens. Radioprotection 54(4): 241-246.
Cooper C. 2016. Citizen science: how ordinary people are changing the face of discovery. New York: Overlook Press.

CRIIRAD. 2011. Extrait - Dossier Japon. Trait d'Union 53: 4-23. Available from: http:/www.criirad.org/actualites/dossier2011/ japon_bis/crms/extrait_Japon.pdf.

Felt U. 2017 . Responsible research and innovation. In: Hand book of genomics, health and society (S. Gibbon, B. Prainsack, S. Hilgartner, J. Lamoreaux, Eds.). Abingdon: Routledge.

Fukushima Booklet Committee. 2015. 10 lessons from FukushimaReducing risks and protecting communities from nuclear disasters. Available from: http://fukushimalessons.jp.

Geoghegan H, Dyke A, Pateman R, West S, Everett G. 2016. Understanding motivations for citizen science. Final report on behalf of UKEOF. University of Reading, Stockholm Environment Institute (University of York) and University of the West of England.

Gricar BG, Baratta AJ. 1983. Bridging the information gap at Three Mile Island: radiation monitoring by citizens. J. Appl. Behav. Sci. 19(1): 35-49.

Haklay M. 2013. Citizen science and volunteered geographic information - overview and typology of participation. In: Crowdsourcing geographic knowledge: Volunteered Geographic Information (VGI) in theory and practice (D.Z. Sui, et al., Eds.) pp. 105-122. Berlin: Springer.

Hasegawa K. 2004. Constructing civil society in Japan: voices of environmental movements. Burwood: Trans Pacific Press.

Hasegawa K. 2014. The Fukushima nuclear accident and Japan's civil society: context, reactions, and policy impacts. Int. Sociol. 29(4): 283-301.

Hayashi F, Sanpei M, Ohira T, Nakano H, Okazaki K, Yasumura S, Nakajima S, Yabe H, Suzuki Y, Kamiya K. 2020. Changes in the mental health status of adolescents following the Fukushima Daiichi nuclear accident and related factors: Fukushima Health Management Survey. J. Affect. Disord. 260: 432-439.

Irwin A. 1995. Citizen science: a study of people, expertise and sustainable development. New York: Routledge.

Karz A, et al. 2014. Ongoing mental health concerns in post-3/11 Japan. Ann. Glob. Health 80(2): 108-114.

Kenens J, Van Oudheusden M, Yoshizawa G, Van Hoyweghen I. 2020. Science by, with and for citizens: rethinking 'citizen science' after the 2011 Fukushima disaster. Palgrave Communications.

Kimura AH. 2016. Radiation brain moms and citizen scientists: the gender politics of food contamination after Fukushima. Durham: Duke University Press.

Kobori H, Dickinson JL, Washitani I, Sakurai R, Amano T, Komatsu N, Kitamura W, Takagawa S, Koyama K, Ogawara T, MillerRushing AJ. 2016. Citizen science: a new approach to advance ecology, education and conservation. Ecol. Res. 31: 1-19.

Leblanc RM. 1999. Bicycle citizens: the political world of the Japanese housewife. California: University of California Press.

McCormick S. 2012. After the gap: risk assessment, citizen science, and disaster recovery. Ecol. Soc. 17(4): 31.

Morita A, Blok A, Kimura S. 2013. Environmental infrastructures of emergency: the formation of a civic radiation monitoring map during the Fukushima disaster. In: Nuclear disaster at Fukushima Daiichi: social, political and environmental issues (R. Hindmarsh, Ed.) pp. 78-96. New York: Routledge.

Morris-Suzuki T. 2014. Touching the grass: science, uncertainty and everyday life from Chernobyl to Fukushima. Sci. Tech. Soc. 19(3): 331-362.

National Diet of Japan. 2012. The Official Report of the Fukushima Nuclear Accident Independent Investigation Commission (NAIIC). Executive summary. 
National Network of Parents to Protect Children from Radiation. Overview of network groups [in Japanese]. Available from: http:// kodomozenkoku.sakura.ne.jp/network.html (accessed 8/01/2020).

Pearce F. 2018. What was the fallout from Fukushima? The Guardian.
Silvertown J. 2009. A new dawn for citizen science. Trends Ecol. Evol. 24(9): 467.

Walsh EJ. 1981. Resource mobilization and citizen protest in communities around Three Mile Island. Soc. Probl. 29(1): 1-21.

Cite this article as: Kenens J. 2020. Changing perspectives: tracing the evolution of citizen radiation measuring organizations after Fukushima. Radioprotection 55(HS2): S249-S253 